\title{
ВАЛЕОЛОГІЧНА ТОЧКА ЗОРУ НА ПЕРСОНІФІКОВАНУ МЕДИЦИНУ
}

\author{
В. В. Вишневський, В. А. Гаврилюк ${ }^{1}$ \\ Інститут проблем математичних машин і систем НАН України \\ ${ }^{1}$ Національна медична академія післядипломної освіти імені П. Л. Шупика
}

\begin{abstract}
У статті ссрормована валеологічна точка зору на персоніфіковану медицину. Автори аналізують досяжність таких цільових орієнтирів охорони здоров'я як «збільшення тривалості життя» та «підвищення рівня благополуччя» в їх системному взаємозв'язку. Виходячи з принципової можливості кількісного виміру рівня індивідуального здоров'я, вводиться нове поняття - «індивідуальна траєкторія здоров'я». На основі аналізу ідеалізованих індивідуальних траєкторій здоров'я в дев'ятнадцятому сторіччі та в даний час, наведено недоліки цільового орієнтиру «тривалість життя» для сучасного стану охорони здоров'я. Показана необхідність зміни парадигми «персоніфрікованої медицини» для забезпечення досяжності інших цільових орієнтирів охорони здоров'я, зокрема «підвищення рівня благополуччя». Відповідно до запропонованої точки зору, метою та змістом персоніфікованої медицини має стати цілеспрямована діяльність лікаря та пацієнта у напряму управління індивідуальною траєкторією здоров'я пацієнта. В основу цієї діяльності має бути покладено постійний моніторинг кількісного оцінювання здоров'я пацієнта протягом усього його життя.
\end{abstract}

Ключові слова: цільові орієнтири охорони здоров'я, персоніфрікована медицина, індивідуальна траєкторія здоров'я.

\section{VALEOLOGICAL VIEWPOINT FOR PERSONIFIED MEDICINE}

\author{
V. V. Vishnevskey, V. A. Gavrylyuk ${ }^{1}$ \\ Institute of Mathematical Machines and Systems problems of NAS of Ukraine \\ ${ }^{1}$ Shupyk National Medical Academy of Postgraduate Education
}

\begin{abstract}
Background. The valueological viewpoint on personalized medicine is formed in the article. The authors analyze the attainability of such EU health targets as «increasing lifespane» and «increasing well-being» in their systemic relationship. The article provides a brief overview of valeological health assessment systems. The review focuses on the system of Dr. Apanasenko, one of the founders of the Ukrainian school of valeology. This system has been tested for over 30 years.

Materials and methods. Results. The presence of these systems explains the fundamental possibility of quantitative measurement of the level of individual health. The authors use this possibility to introduce a new definition - «individual health trajectory».

Based on the analysis of idealized individual health trajectories in the nineteenth century and now, the authors shows the shortcomings of the target «lifespane» for the current state of health care. It is shown that at present the average «individual health trajectories» of patients are such that an increase in life expectancy is achieved in conditions of a low level of individual health of the patient. In fact, we are talking about extending life in a chronic disease and reducing wellbeing. To ensure the reach of the health target of «increasing well-being», the necessity of changing the paradigm of «personalized medicine» is shown.

Conclusions. According to the authors, the goal and content of personalized medicine should be the focused activity of the doctor and patient in the direct of managing the individual trajectory of the patient's health. This activity should be based on constant monitoring of a quantitative assessment of the patient's health throughout his life. A new mobile devices and information technologies can be used to support this activity.
\end{abstract}

Key words: health targets, health, personified medicine, individual health trajectory.

\section{ВАЛЕОЛОГИЧЕСКАЯ ТОЧКА ЗРЕНИЯ НА ПЕРСОНИФИЦИРОВАННУЮ МЕДИЦИНУ}

\author{
В. В. Вишневский, В. А. Гаврилюк ${ }^{1}$ \\ Институт проблем математических машин и систем НАН Украины \\ ${ }^{1}$ Национальная медицинская академия последипломного образования имени П. Л. Шупика \\ В статье ссрормирована валеологическая точка зрения на персонифицированную медицину. Исходя из анализа \\ целевых ориентиров здравоохранения и принципиальной достижимости количественного измерения уровня индиви- \\ дуального здоровья, вводится понятие «индивидуальная траектория здоровья». Показано, что мониторинг и управ- \\ ление этой траекторией следует рассматривать в качестве цели и содержания персонисицированной медицины.
}

Ключевые слова: целевые ориентиры здравоохранения, здоровье, персонисрицированная медицина, индивидуальная траектория здоровья.

(c) В. В. Вишневський, В. А. Гаврилюк 
Вступление. Как известно, в 2012 г. все 53 государства-члены Европейского региона Всемирной организации здравоохранения (ВО3) приняли политику «Здоровье-2020» — новую общую основу европейской политики в области здравоохранения [1, 2]. Эта политика поддерживает действия государства и общества, направленные на улучшение здоровья и повышение уровня благополучия населения, сокращение неравенства, укрепление общественного здравоохранения, а также обеспечение наличия систем здравоохранения, ориентированных на нужды людей, характеризующихся высоким качеством помощи и соблюдением принципов всеобщего охвата населения, социальной справедливостью и устойчивостью. В 2013 г. государства-члены утвердили систему целевых ориентиров, одним из которых является «повышение средней продолжительности жизни» при одновременном «повышении уровня благополучия» населения.

Результаты национальных программ стран ЕС по достижению этих целевых ориентиров станут известны уже в 2021 году, но, судя по тяжелым пандемиям последних лет, вряд ли эти результаты будут оптимистическими. Тем не менее, следует отметить, что среди возможных путей достижения этих целевых ориентиров эксперты выделяют новые подходы так называемой «персонифицированной медицины». Но вот мнения экспертов относительно содержания и методов самой персонифицированной медицины пока значительно расходятся [3-5].

Цель работы: сформулировать валеологическую точку зрения на персонифицированную медицину, которая, на наш взгляд, должна сводиться к научнообоснованным методам управления индивидуальной траекторией здоровья конкретного человека на протяжении всей его жизни с момента рождения и до исхода.

Результаты и их обсуждение. Формируя валеологическую точку зрения по этой теме будем исходить из того обстоятельства, что на сегодня уже существует целый ряд методов количественной оценки уровня здоровья (Health level) [6-11], в том числе апробированный на протяжении более 30 лет метод количественного измерения уровня индивидуального здоровья по экспресссистеме Апанасенко [8-10]. Последняя состоит в следующем: способность накапливать энергию в макроэргических связях является универсальной функцией всего организма в целом. Именно эта функция обеспечивает неравновесное состояние биосистемы - жизнь, а её количественная характеристика может служить основой для оценки совершенства и жизнеспособности конкретного организма. Чем больше резерв энергии на единицу массы живой системы, тем она устойчивее к внешним воздействия.

Положение об источниках и характере энергии, обеспечивающих функционирование живых систем, о применимости к ним второго начала термодинамики высказаны Э. С. Бауэром еще в 1935 году.

Проблема измерения степени жизнеспособности, которой можно характеризовать уровень соматического здоровья, упирается в проблему оценки потенциала аэробного энергообразования, что, в свою очередь, свидетельствует об эффективности деятельности аппарата митохондрий $[12,13]$.

С физиологической точки зрения, этот показатель интегрально характеризует состояние дыхательной, кровеносной и метаболической функций.

С биологической точки зрения - характеризует степень устойчивости (жизнеспособности) неравновесной системы - живого организма.

В системе Апанасенко [6-8] используются простейшие индексы функций, характеризующие функциональный резерв (силовой и дыхательный индексы) и экономизацию функций («двойное произведение» и время восстановления частоты пульса после стандартной нагрузки).

Показатели ранжированы, каждому рангу присвоен свой балл, а суммой баллов характеризуется уровень здоровья (жизнеспособности). Установлено, что сумма баллов имеет высокий коэффициент корреляции с МПК (около 0,8). Выделяется 5 уровней здоровья. Такой подход предоставляет следующие возможности:

- имея возможность «измерить» индивидуальное здоровье, можно построить «шкалу здоровья», которая при динамическом мониторинге позволяет отслеживать индивидуальную траекторию здоровья;

- чем выше уровень здоровья, тем меньше вероятность развития эндогенных факторов риска и манифестированных форм заболеваний;

- существует «безопасный» уровень здоровья, выше которого не определяются ни эндогенные факторы риска, ни манифестированные формы заболеваний. Ему дана количественная оценка;

- при выходе индивида из «безопасной зоны» здоровья отмечается феномен «саморазвития» патологического процесса; 
- имея количественные показатели траектории здоровья, ими можно управлять (формировать, сохранять, восстанавливать);

- возвр щение в «безопасную зону» здоровья практически здоровых людей — наиболее эффективный путь первичной профилактики хронических неинфекционных заболеваний (ХНИЗ).

На текущий момент, система количественной оценки индивидуального здоровья по Апанасенко, «пожалуй единственная, целиком сложившаяся, апробированная и специфичная» [11]. Обсуждение сути всех существующих систем оценки здоровья [6-13] далеко выходит за рамки этой статьи, но для нашего анализа важно, что такие системы уже существуют и развиваются. А значит, могут быть использованы и в персонифицированной медицине.

Попробуем проиллюстрировать наш взгляд всего на одном рисунке с графиками траекторий здоровья (рис. 1). По оси ординат на графике будем показывать «уровень здоровья», а оси абсцисс время жизни.

Пунктирная линия 1 показывает уровень «безопасного» здоровья, а пунктирная линия 2 - разделяет уровни, еще соответствующие состоянию преобладания здоровья и состоянию преобладания болезни. Вполне очевидно, что при таком представлении траектории жизни метрика «продолжительность жизни» сводится к проекции графика траектории на ось абсцисс.

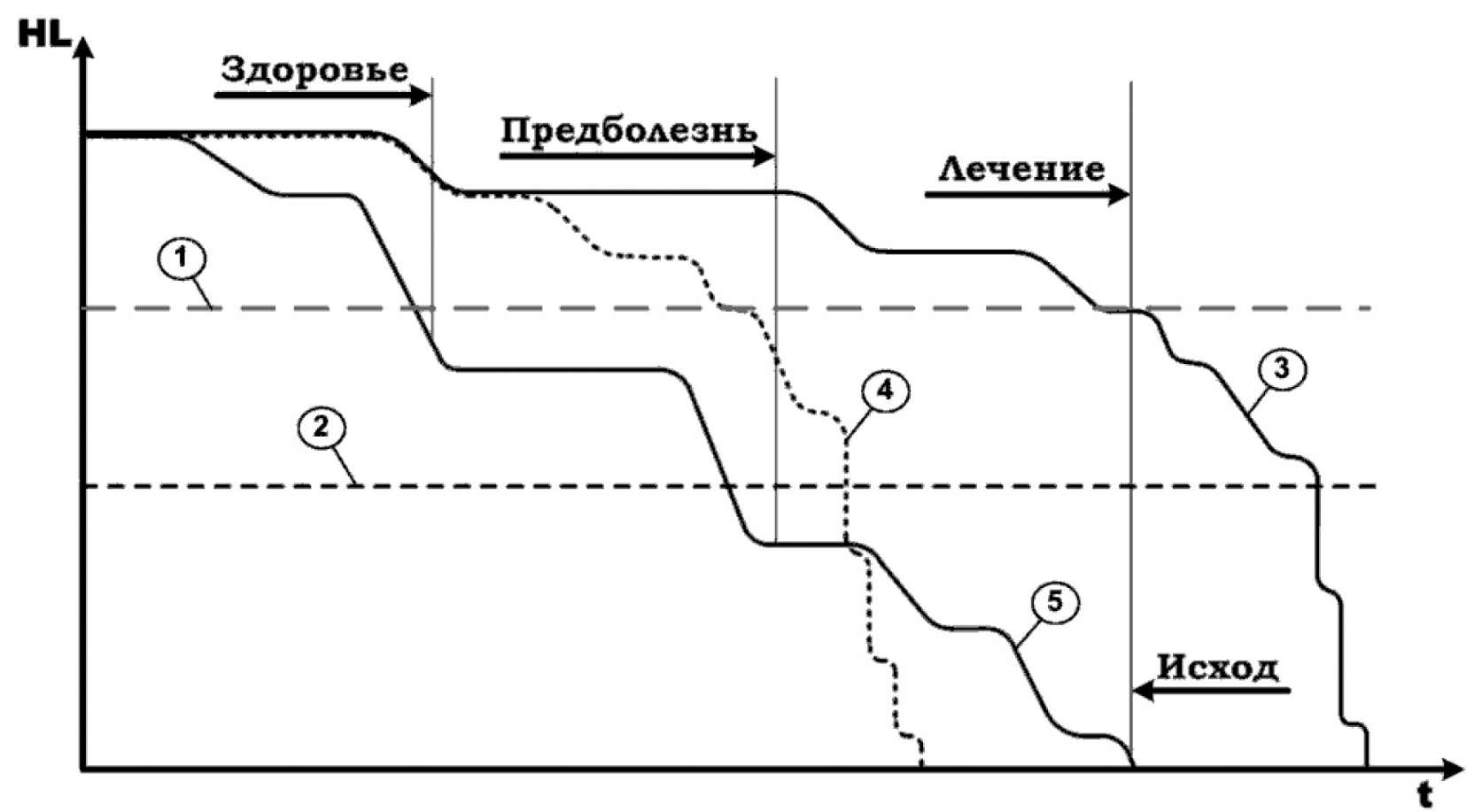

Рис. 1. Идеализированные и реальные траектории здоровья индивида

Графиком 4 иллюстрируем некую обобщенную траекторию здоровья человека в 19 веке. Средняя продолжительность жизни составляла тогда около 40 лет. Но при этом большую часть своей жизни человек той эпохи находился в состоянии «безопасного уровня здоровья», однако в случае острого заболевания достаточно быстро переходил в состояние преобладания болезни и уходил из жизни. Именно в этот исторический период было предложено характеризовать уровень здравоохранения простым и понятным статистическим показателем «средняя продолжительность жизни». Представляется, что не очень отклонимся от истины, если предположим, что врачи того времени ставили перед собой в качестве цели достижение траектории жизни вида 3. Когда продолжительность жизни увеличивается, но сама форма траектории остается прежней. Возможно, совершенно не зря такая идеализированная траектория жизни людей до нас дошла в виде сказочной фразы «... они жили долго и счастливо и умерли в один день...». А говоря более математическим языком, метрику цели «средняя продолжительность жизни» нужно было бы рассчитывать не в виде проекции графика на одну ось, а в виде площади под графиком. Тогда задача здравоохранения также состояла бы в максимизации значения этой метрики, но вполне гармонично была бы объединена с целевым ориентиром 
«повышения уровня благополучия населения», поскольку именно через понятие «благополучие» ВО3 определяет понятие «здоровье».

Но, в реальности сейчас имеем ситуацию, когда некая обобщенная траектория жизни имеет вид 5. А большинство усилий современной медицины сосредоточено как раз на том этапе жизни, когда человек уже находится в состоянии преобладания болезни и вполне по праву называется пациентом. Конечно, говоря военным языком, «битву за продолжительность жизни» человечество выигрывает, но вот войну за жизнь в состоянии «безопасного уровня здоровья» проигрывает. На смену острым, преимущественно инфекционным и ассоциированным с инфекциями заболеваниям в ХХ веке пришли хронические неинфекционные заболевания (ХНИЗ). И хорошо отработанные стратегии и тактики лечения прежних болезней, сокращавших жизнь, в данном случае не столь эффективны. Лечение становится дорогим и продолжительным, часто пожизненным. Фактически, речь идет о поддержании жизни и ее качества в условиях продолжающегося ухудшения здоровья, а не об обеспечении «гарантированного уровня здоровья» (или высокого уровня благополучия в терминах ВО3) [14-16].

На наш взгляд, приведенное обобщенное графическое представление идеальной и

\section{Литература.}

1. Целевые ориентиры и более широкая перспектива новые рубежи в работе с фактическими данными. Доклад о состоянии здравоохранения в Европе. Копенгаген: Европейское региональное бюро ВО3, 2015. - Режим доступа: http://www.euro.who.int/ru/ data-and-evidence/european-health-report2015.

2. «Здоровье-2020» - основы европейской политики и стратегия для XXI века. - Копенгаген: Европейское региональное бюро ВОЗ, 2013. - Режим доступа: http://www.euro.who.int/ru/publications/ abstracts/health-2020-a-european- policy-frameworkand-strategy-for-the- 21st-century.

3. Jain K. K. Textbook of Personalized Medicine / Jain K. K. — New York: Springer, 2009. — 419 p.

4. Файнзильберг Л. С. Об одном подходе к персонификации диагностических решений на примере оценки сердечной деятельности / Файнзильберг Л. С. // Кибернетика и вычислительная техника. - 2014. - Вып. 178. - С. 52-65.

5. Реальні горизонти персоналізованої медицини. Стратегія та варіанти розвитку / Мінцер О. П., Вишневский В. В. // Медична інформатика та інженерія. — 2016. — № 4 (36). — С. 7-11. реальной траекторий жизни вполне убедительно показывает, что целью персонификации медицины должны стать разработки подходов для персонифицированных методов управления траекториями здоровья. Причем таким образом, чтобы большую часть своей жизни человек находился в состоянии гарантированного здоровья. Поэтому все медицинские сервисы и приборы должны рассматриваться и специализироваться с учетом того периода траектории здоровья, для которого они применяются. Поскольку концентрация усилий только на сложных диагностических процедурах этапа «Лечение» априори означает, что целевые ориентиры здравоохранения в их системной взаимосвязи достичь не удастся никогда.

Выводы. Первым правильным шагом в сторону персонифицированной медицины должно быть введение на первичном уровне медицинской помощи постоянного количественного мониторинга уровня здоровья населения при помощи современных мобильных платформ и облачных сервисов. Именно таким инновационным технологиям должны быть посвящены новые исследовательские проекты персонифицированной медицины, особенно в домашнем и мобильном исполнении.

6. Перхуров А. М. Очерки донозологической функциональной диагностики в спорте / Перхуров А. М. - М.: РАСМИРБИ, 2006. - 290 с.

7. Введение в системную медицину: общие вопросы и методология, аспекты диагностики, профилактики и лечения / Козлов В. К., Ярилов С. В. - Санкт-Петербург, 2010.

8. Апанасенко Г. Л. Эволюция биоэнергетики и здоровье человека / Апанасенко Г. Л. - С-Пб: Петрополис. - 1992. - 138 c.

9. Человек: эволюция, здоровье, бессмертие / Апанасенко Г. Л., Гаврилюк В. А. - Винница: Вінницька газета, 2014. - 320 с.

10. Индивидуальное здоровье: в поисках сущности и критериев количественной оценки // Довкілля та здоров’я. - 2015. - № 3. - С. 8-12.

11. Инфекционные болезни и проблемы адаптации / Ю. В. Лобзин, Ю. П. Финогеев, В. М. Волжанин и др. - Санкт-Петербург: Элби-СПб, 2006. - 392 с.

12. Рэкер Э. Биоэнергетические механизмы: новые взгляды / Э. Рэкер. - М.: Мир, 1979. - 216 с.

13. Романчук А. П. Современные подходы к оценке кардиореспираторных взаимодействий у спортсменов / Романчук А. П. - Одесса: Астропринт, 2006. - 232 c. 
14. Профілактика неінфекційних захворювань / під ред. О. М. Біловола, Г. Д. Фадєєнко. - К.: Здоров’я України, 2016. - 368 с.

15. Рівень здоров’я і фізіологічні резерви організму / Г. Л. Апанасенко, Л. Долженко // Теорія і методика фізичного виховання і спорту. — 2007. — № 1. С. $17-21$.

16. Диагностическая эффективность методов количественной оценки индивидуального здоровья / Безматерных Л. Э., Куликов В. П. // Физиология человека. - 1998. — № 3. - С. 79-85.

\section{References.}

1. (2015). Celevye orientiry i bolee shirokaya perspektiva novye rubezhi v rabote s fakticheskimi dannymi. Doklad o sostoyanii zdravoohraneniya v Evrope. [The European Health report is produced every three years as a flagship publication by the WHO Regional Office for Europe]. Copenhagen: WHO Regional Office for Europe. http:// www.euro.who.int. Retrieved from: http://www.euro.who. int/ru/data-and-evidence/european-health-report2015.

2. (2020). Zdorove-2020 - osnovy evropejskoj politiki $i$ strategiya dlya HHI veka. [Health 2020: the European policy for health and well-being]. Copenhagen: WHO Regional Office for Europe. http://www.euro.who.int. Retrieved from: http://www.euro.who.int/ru/healthtopics/health-policy/health-2020-the-european-policyfor-health-and-well-being.

3. Jain, K. K. (2009). Textbook of Personalized Medicine. New York: Springer.

4. Fajnzilberg, L. S. (2014). Ob odnom podhode k personifikacii diagnosticheskih reshenij na primere ocenki serdechnoj deyatelnosti. Kibernetika $i$ vychislitelnaya tehnika, 178, 52-65. [In Russian].

5. Mintser, O. P., Vishnevskey, V. V. (2016). Realni gorizonti personalizovanoyi medicini. Strategiya ta varianti rozvitku. Medichna informatika ta inzheneriya, 4 (36), 7-11. [In Ukrainian].
6. Perhurov, A. M. (2006). Ocherki donozologicheskoj funkcionalnoj diagnostiki v sporte. Moskva (Moscow): RASMIRBI. [In Russian].

7. Kozlov, V. K., Yarilov, S. V. (2010). Vvedenie v sistemnuyu medicinu: obshie voprosy i metodologiya, aspekty diagnostiki, profilaktiki i lecheniya. SanktPeterburg (St. Petersburg). [In Russian].

8. Apanasenko, G. L. (1992). Evolyuciya bioenergetiki i zdorove cheloveka. S-Pb (St. Petersburg): MGP Petropolis. [In Russian].

9. Apanasenko, G. L., Gavrilyuk, V. A. (2014). Chelovek: evolyuciya, zdorove, bessmertie. Vinnica: Vinnicka gazeta. [In Russian].

10. (2015). Individualnoe zdorove: v poiskah sushnosti i kriteriev kolichestvennoj ocenki. Dovkillya ta zdorov'ya, 3, 8-12. [In Russian].

11. Lobzin, Yu. V., Finogeev, Yu. P., Volzhanin,V. M., Semena, A. V., Zaharenko, S. M. (2006). Infekcionnye bolezni i problemy adaptacii. Sankt-Peterburg (St. Petersburg): Elbi-SPb. [In Russian].

12. Reker, E. (1979). Bioenergeticheskie mehanizmy: novye vzglyady. Moskva (Moscow): Mir. [In Russian].

13. Romanchuk, A. P. (2006). Sovremennye podhody kocenke kardiorespiratornyh vzaimodejstvij u sportsmenov. Odessa: Astroprint. [In Russian].

14. Bilovol, O. M. , Fadyeyenko, G. D. (Ed.). (2016). Profilaktika neinfekcijnih zahvoryuvan. Kiyiv (Kyiv): Zdorov'ya Ukrayini. [In Ukrainian].

15. Apanasenko, G. L. (2007). Riven zdorov’ya i fiziologichni rezervi organizmu. Teoriya i metodika fizichnogo vihovannya i sportu: naukovo-teoretichnij zhurnal, 1, 17-21. [In Ukrainian].

16. Bezmaternyh, L. E. (1998). Diagnosticheskaya effektivnost metodov kolichestvennoj ocenki individualnogo zdorovya. Fiziologiya cheloveka, 3, 79-85. [In Ukrainian]. 